\title{
INFESTATION BY Aedes albopictus (SKUSE) IN NATURAL AND ARTIFICIAL BREEDING SITES FOUND IN GREEN AREAS IN THE CITY OF FORTALEZA, CEARÁ
}

Thesis: C. H. M. Alencar submitted this thesis for his Masters in Public Health at Community Health Department, Federal University of Ceará, UFC, Fortaleza, Ceará State, Brazil, 2008.

Advisor: Professor Ricardo José Soares Pontes

ABSTRACT: Aedes albopictus mosquito is a vector of several different arboviruses and uses natural breeding sites for its reproduction. The objective of this study was to describe the determinants of Aedes albopictus infestation in verdant areas of Fortaleza, Ceará (Brazil). It is a descriptive, exploratory study conducted in four city areas with high vegetation density and presence of natural breeding sites. The environmental, populational and physical aspects of these areas were detailed as well as the possibility that they serve as a source of protection for viable eggs in the dry season. The study was composed of two parts carried out throughout 2007. The first was undertaken during the rainy season with water samples obtained from natural and artificial breeding sites. The second took place in the dry season and samples were collected only from the natural breeding sites. These areas were classified in accordance with the literature and correlated with the presence of immature forms of Aedes albopictus. During the rainy period, of the 62 breeding areas in existence, 49 (79\%) were natural and of these, 25 (51\%) were infested with Aedes albopictus. Among the trees that tested positively in these areas, the genera Terminalia, Acacia, Bambusa and Magnifera stood out, while in the artificial breeding sites tires, opened coconuts and small plastic containers were most common. Aedes albopictus was the lone inhabitant of 24 (96\%) of the natural breeding sites and the greatest density of larvae was found in areas of lesser vegetation and closer to the soil, whereas tires held the higher density within the artificial areas. Nine (37.5\%) 
natural breeding sites continued to be infested in the two seasons and five others only in the rainy season (14; 30.4\%; $\mathrm{Cl} 95 \%$ : 16.62-44.25). In general terms, there was infestation of $51.0 \%$ of natural breeding only in the rainy season, $30.4 \%$ only in the dry season and $63.8 \%$ if considered in totality. One can conclude that trees of several genera in natural breeding areas offer adequate conditions for the development of immature forms of Aedes albopictus in several stages. In this sense, there may be expanded propagation in the next rainy season in the urban areas of Fortaleza. This scenario amplifies the challenges inherent in the control of dengue fever and other infectious diseases transmitted by this vector.

KEY WORDS: vector control, dengue, epidemiology, Aedes albopictus.

\section{CORRESPONDENCE TO:}

CARLOS HENRIQUE MORAIS DE ALENCAR, Departamento de Saúde Comunitária, Faculdade de Medicina, UFC, Fortaleza, CE, Brasil. Phone: +55 85 3366 8045. Fax: +55 853366 8045. Email: carllosalencar@yahoo.com.br. 